\title{
Genotype by Environment Interaction Analysis for Tuber Yield of Potato (Solanum tuberosum L.) Using a GGE Biplot Method in Amhara Region, Ethiopia
}

\author{
Mulugeta Gedif ${ }^{*}$, Dessalegn Yigzaw ${ }^{2}$ \\ ${ }^{1}$ Horticulture, Adet Agricultural Research Center, Bahirdar, Ethiopia \\ ${ }^{2}$ Horticulture, Amhara Region Agricultural Research Institute, Bahirdar, Ethiopia \\ Email: segedif@gmail.com
}

Received 10 December 2013; revised 5 February 2014; accepted 19 February 2014

Copyright (C) 2014 by authors and Scientific Research Publishing Inc.

This work is licensed under the Creative Commons Attribution International License (CC BY). http://creativecommons.org/licenses/by/4.0/

(c) $\underset{\mathrm{EY}}{0}$ Open Access

\begin{abstract}
Potato is one of the important crops grown in mid and high altitude areas of Ethiopia. Several potato genotypes have been introduced in different parts of this region. However, the stability and performance of these genotypes are not yet assessed. Therefore, the objective of this study was to determine the effect of genotype, environment and their interaction for tuber yield and identify stable potato genotypes. The study was conducted using eight potato genotypes in rainfed production season of years 2010 and 2011 at five potato growing locations in the region. Randomized complete block design with three replications was used for the experiment. Among the testing locations, the superior mean tuber yield $(25.43 \mathrm{t} / \mathrm{ha})$ was obtained at Adet while the inferior $(13.89$ t/ha) was at Injibara. Similarly, among the genotypes, CIP-396004.337 gave the highest mean tuber yield (25.66 t/ha), while CIP-395011.2 gave the lowest (17.78 t/ha). Combined ANOVA indicated that the main effects due to environments, genotypes and genotype by environment interaction were highly significant. The contribution of $E, G$ and GEI to the total variation in tuber yield was about $47.11 \%, 8.83 \%$ and $44.07 \%$, respectively. The GEI was further partitioned using GGE biplot model. The first two principal components obtained by singular value decomposition of the centered data of tuber yield explained $71.26 \%$ of the total variability caused by (G + GE). Out of these variations, PC1 and PC2 accounted $51.24 \%$ and $\mathbf{2 0 . 0 2 \%}$ variability, respectively. GGE biplot view of this study identified Serinka as ideal testing location and CIP-396004.337 as ideal genotype for Amhara region in Ethiopia.
\end{abstract}

\section{Keywords}

G; GxE; GEI; Ideal Environment; Ideal Genotype

\footnotetext{
${ }^{*}$ Corresponding author.

How to cite this paper: Gedif, M. and Yigzaw, D. (2014) Genotype by Environment Interaction Analysis for Tuber Yield of Potato (Solanum tuberosum L.) Using a GGE Biplot Method in Amhara Region, Ethiopia. Agricultural Sciences, 5, $239-249$. http://dx.doi.org/10.4236/as.2014.54027
} 


\section{Introduction}

The potato has its origin in the high Andes of South America. It was introduced to Ethiopia in 1858 by the German botanist Shimper [1]. Since then, it has served as food and cash crop for small scale farmers. Among root and tuber crop in Ethiopia, potato presently ranks first in volume produced and consumed followed by Cassava, Sweet Potato and Yam [2]. In Ethiopia, about 70\% of the available agricultural land is located at an altitude of 1800 - 2500 m.a.s.l. This region receives an annual rainfall of more than $600 \mathrm{~mm}$, which is suitable for potato production [3].

Even though the country has suitable environmental conditions, the regional ( $9.35 \mathrm{t} / \mathrm{ha})$ as well as the national (7.99 t/ha) productivity of potato is very low [2] as compared to the world average of $17.16 \mathrm{t} / \mathrm{ha}$ [4]. A number of production problems that account for low regional as well as national yield have been identified. These include the lack of stable, well-adapted disease and insect pests' tolerant varieties, [5].

The farmers need varieties that show high performance for yield and other essential agronomic traits. Their superiority should be reliable over a wide range of environmental conditions and also over years. The basic cause for difference in the performance of genotypes over environments is the occurrence of genotype-environment interaction (GEI). To overcome GEI problem, trials are usually conducted over several locations and years to ensure that the selected genotypes have a high and stable performance over a wide range of environments.

The data generated in these trials are analysed for GEI by various methods. The most recent method GGE biplot model [6], provides breeders with a complete and visual evaluation of all aspects of the data by creating a biplot that simultaneously represents both mean performance and stability, optimized environments for specific genotypes and identifies mega-environments. To date, little information is available on marketable tuber yield of potato varieties and their adaptation under diverse environmental condition in Amhara region/Ethiopia. The present study was, therefore, conducted to generate relative information using GGE biplot model to assess the nature and magnitude of GEI and determine the response of different genotypes to varying environments to identify high yielding stable potato genotypes for the Amhara region/Ethiopia.

\section{Materials and Methods}

The experiment was carried out with eight potato genotypes; CIP-396033.102, CIP-395120.36, CIP-396004.337, CIP-395096.2, CIP-395111.13, CIP-395011.2, CIP-396031.108, and CIP-396004.225. All genotypes were introduced from the International Potato Center (CIP). The trials were conducted in rainfed seasons of years 2010 and 2011 at five different potato growing locations with a total of 10 environments (Table 1). Planting was done in May in plots of $3 \mathrm{~m} \times 3 \mathrm{~m}$ size in randomized complete block design with three replicates. The tubers were planted at $0.75 \mathrm{~m} \times 0.3 \mathrm{~m}$ inter-row and intra-row spacing, respectively. Fertilization and crop management practices were applied as per recommendations for the specific area/location [7]. Tuber yield was taken from 16 plants of middle rows and computed to hectare. Tubers greater than $30 \mathrm{~mm}$ diameter were considered as marketable. The data were analyzed by using SAS [8] (ANOVA) and Genstat $14^{\text {th }}$ ed. [9] (GGE biplot). LSD was used for mean separation.

The locations were considered as random and genotypes as fixed effects, and a mixed effect model ANOVA was used for statistical analysis. In the ANOVA, sources of partitioned variances include blocks, treatments and

Table 1. Description of the test environments of the field experiment.

\begin{tabular}{cccccccc}
\hline \multirow{2}{*}{ Experimental Site } & Geographical Location & Elevation (m.a.s.l.) & \multicolumn{2}{c}{ Soil Properties } & \multicolumn{2}{c}{ Climate Data } \\
\cline { 3 - 6 } & & & PH & Texture & RF (mm) & Temp. $\left({ }^{\circ} \mathrm{C}\right)$ \\
\hline Adet & $11^{\circ} 16^{\prime} 30.3^{\prime \prime} \mathrm{N}, 37^{\circ} 30^{\prime} 1.8^{\prime \prime} \mathrm{E}$ & 2240 & 5.20 & Heavy & 1005.54 & 18.60 \\
Debretabor & $11^{\circ} 51^{\prime} 0^{\prime \prime} \mathrm{N}, 38^{\circ} 1^{\prime} 0^{\prime \prime} \mathrm{E}$ & 2630 & 4.94 & Clay & 1416.15 & 17.14 \\
Injibara & $10^{\circ} 57^{\prime} 0^{\prime \prime} \mathrm{N}, 36^{\circ} 56^{\prime} 0^{\prime \prime} \mathrm{E}$ & 2610 & 4.50 & Clay & 2175.37 & 15.18 \\
Sirinka & $11^{\circ} 49^{\prime} 00^{\prime \prime} \mathrm{N}, 39^{\circ} 38^{\prime} 00^{\prime \prime} \mathrm{E}$ & 1850 & 5.02 & Clay & 945 & 19.16 \\
Debrebirhan & $12^{\circ} 37^{\prime} 0^{\prime \prime} \mathrm{N}, 37^{\circ} 29^{\prime} 0^{\prime \prime} \mathrm{E}$ & 2800 & 5.83 & Clay & 1728 & 15.84 \\
\hline
\end{tabular}

Note: the mean rainfall data and temperature shown above is only the average of the growing months from May through September. 
error terms. The treatment was broken down into three components: G, E and GEI effects in the following equation [6]:

$$
Y_{i j r}=\mu+\alpha_{i}+\beta_{j}+\alpha \beta_{i j}+b_{j}+\varepsilon_{i j r}
$$

where $y_{i j r}$, is the average value of the dependent variable of genotype $i$ in environment $j$ and block $r, \mu$ is a grand mean, $\alpha_{i}$ is the effect of the $i^{\text {th }}$ genotype. $\beta_{j}$, is the effect of the $j^{\text {th }}$ environment, $\alpha \beta_{i j}$ is the effect of the $i^{\text {th }}$ genotype by the $j^{\text {th }}$ environment, $b_{j}$ is the block effect at the $j^{\text {th }}$ environment and $\varepsilon_{i j}$, is the residual error term.

Stability Analysis: GE interaction analysis was done by GGE biplot, which uses singular value decomposition (SVD) to decompose GGE into two or more principal components. Each principal component consisted of a set of genotype scores multiplied by a set of environment scores, to generate a two-dimensional biplot [6].

In GGE biplots genotype plus genotype $\times$ environment $(G+G E)$ interaction was studied together and to achieve this G + GE effect is separated out from the observed mean from Equation (1) (by omitting random error and block effect) and eventually model becomes as

$$
Y_{i j}-\mu-\beta_{j}=\alpha_{i}+\alpha \beta_{i j}
$$

The GGE (G + GE) effect was partitioned into multiplicative terms by using SVD. The model based on singular value decomposition (SVD) of first two principal components is:

$$
Y_{i j}-\mu-\beta_{j}=\lambda_{1} \xi_{i 1} \eta_{j 1}+\lambda_{2} \xi_{i 2} \eta_{j 2}+\varepsilon_{i j}
$$

where $Y_{i j}$ is the measured mean of genotype $i$ in environment $j, \mu$ is the grand mean, is the main effect of environment $j, \beta_{j}$ being the mean yield across all genotypes in environment $j, \lambda_{1}$ and $\lambda_{2}$ are the singular values (SV) for the first and second principal components (PC1 and PC2), respectively, and $\xi_{i 1}$ are eigenvectors of genotype $i$ for PC1 and $\xi_{i 2}$ for PC2, respectively, $\eta_{1 j}$ and $\eta_{2 j}$ are eigenvectors of environment $j$ for PC1 and PC2, respectively, $\varepsilon_{i j}$ is the residual associated with genotype $i$ in environment $j$ [6].

PC1 and PC2 eigenvectors cannot be plotted directly to construct a meaningful biplot before the singular values are partitioned into the genotype and environment eigenvectors. Singular value partitioning is implemented by,

$$
g_{i l}=\lambda_{l} f_{l} \xi_{i l} \text { and } e_{l j}=\lambda_{l}^{1-f_{l}} \eta_{l j}
$$

where $f_{l}$ is the partition factor for PC1. Theoretically, $f_{l}$ can be a value between 0 and 1 , but 0.5 is most commonly used.

To generate the GGE biplot, the Formula (4) was presented as:

$$
Y_{i j}-v-\beta_{j}=g_{i 1} e_{1 j}+g_{i 2} e_{2 j}+\varepsilon_{i j}
$$

\section{Results and Discussion}

\subsection{Analysis of Variance}

The analysis of variance for marketable tuber yield (t/ha) for each year/season and combined over years revealed highly significant variations for the genotype, environment and genotype by environment interaction effect (Table 2). The table also indicates that, location was the most important source of yield variation that accounted for $51.51 \%$ and $46.07 \%$ of the total variation (G, L and GL) during 2010 and 2011seasons respectively. Similarly, the contribution of GL in two years was about $38.50 \%$ and $42.23 \%$, respectively. GL was greater than G in both testing years. The same was true for combined data across years/seasons.

The combined analysis of variance across years and locations (Table 2) indicated that mean marketable tuber yield (MTY) was significantly influenced by environments $(\mathrm{L}+\mathrm{Y})$ which accounted for $47.11 \%$ of the total variation, while G and GEI explained $8.83 \%$ and $44.07 \%$ of the variation, respectively. The contribution of years was about $0.21 \%$ (Table 2) which indicated minimal contribution of years to the total variation of MTY.

The mean performance of tested genotypes across testing years and locations ranged from $18.78 \mathrm{t} / \mathrm{ha}$ for G6 to 25.66 t/ha for G3 (Table 3). G6 and G4 had superior MTY at Ad1 (Adet 2010) and Db1 (Debrebirhan 2010) while inferior at Db1 (Debrebirhan 2010) and Ij2 (Injibara 2011), respectively. This indicated the presence of cross over interaction. Mean MTY (t/ha) of testing environments varied from 13.05 t/ha for Ij1 (Injibara 2010) 
Table 2. Genotype (G), environment (L and Y), genotype by environment (GE), variance terms for rainfed potato yield trials in 2010-2011 and combined over these years/seasons.

\begin{tabular}{|c|c|c|c|c|c|}
\hline Year/s & Source & $\mathrm{DF}$ & SS & MS & $\%(L+G+G L)$ \\
\hline \multirow[t]{3}{*}{2010} & Location (L) & 4 & 3117.05 & $779.26^{* *}$ & 51.51 \\
\hline & Genotype (G) & 7 & 604.26 & $86.32^{* *}$ & 9.99 \\
\hline & GL & 28 & 2329.62 & $83.20^{* *}$ & 38.50 \\
\hline \multirow[t]{4}{*}{2011} & Location (L) & 4 & 2332.70 & $583.17^{* *}$ & 46.07 \\
\hline & Genotype (G) & 7 & 592.43 & $84.63^{* *}$ & 11.70 \\
\hline & GL & 28 & 2138.06 & $76.36^{* *}$ & 42.23 \\
\hline & & & & & $\%(L+G+Y+G L+G Y+G Y L)$ \\
\hline \multirow[t]{7}{*}{ Combined } & Location (L) & 4 & 987.91 & $141.13^{* *}$ & 46.90 \\
\hline & Genotype (G) & 7 & 5246.66 & $1311.66^{* *}$ & 8.83 \\
\hline & Year $(\mathrm{Y})$ & 1 & 23.16 & $23.16^{* *}$ & 0.21 \\
\hline & GL & 28 & 3699.38 & $132.12^{* *}$ & 33.07 \\
\hline & GY & 7 & 208.25 & $29.75^{* *}$ & 1.86 \\
\hline & LY & 4 & 223.76 & $55.94^{* *}$ & 2.00 \\
\hline & GLY & 28 & 798.64 & $28.52^{* *}$ & 7.14 \\
\hline
\end{tabular}

${ }^{* *}$ Significant at $(\mathrm{p}<0.01)$

Table 3. Mean marketable tuber yield (t/ha) of eight potato genotypes across 10 environments in 2010-2011.

\begin{tabular}{|c|c|c|c|c|c|c|c|c|c|c|c|c|}
\hline \multirow{2}{*}{$\begin{array}{l}\text { Genotype } \\
\text { Code }\end{array}$} & \multirow{2}{*}{ Genotypes } & \multicolumn{5}{|c|}{ During 2010 season } & \multicolumn{5}{|c|}{ During 2011 season } & \multirow{2}{*}{$\begin{array}{c}\text { Combined } \\
\text { mean }\end{array}$} \\
\hline & & Ad1 & Ij1 & Sr1 & Db1 & Dt1 & Ad2 & Ij2 & Sr2 & $\mathrm{Db} 2$ & Dt2 & \\
\hline 1 & CIP-396033.102 & $18.01^{\mathrm{d}}$ & $11.73^{\mathrm{bc}}$ & $23.51^{\mathrm{ab}}$ & $24.95^{\mathrm{cd}}$ & $25.75^{\mathrm{bcd}}$ & $25.62^{b}$ & $14.26^{\mathrm{b}}$ & $24.71^{\mathrm{a}}$ & $23.27^{\mathrm{c}}$ & $20.00^{c}$ & $21.18^{\mathrm{c}}$ \\
\hline 2 & CIP-395120.36 & $23.85^{\mathrm{bc}}$ & $11.26 b^{c}$ & $24.15^{\mathrm{ab}}$ & $34.64^{\mathrm{a}}$ & $22.47^{\mathrm{d}}$ & $23.76^{\mathrm{b}}$ & $14.33^{\mathrm{b}}$ & $19.60^{\mathrm{c}}$ & $33.86^{\mathrm{a}}$ & $23.43^{\mathrm{b}}$ & $23.13^{\mathrm{b}}$ \\
\hline 3 & CIP-396004.337 & $28.10^{\mathrm{ab}}$ & $22.37^{\mathrm{a}}$ & $19.63^{\mathrm{cd}}$ & $32.50^{\mathrm{b}}$ & $29.75^{\mathrm{b}}$ & $31.22^{\mathrm{a}}$ & $14.80^{\mathrm{ab}}$ & $21.78^{\mathrm{bc}}$ & $30.51^{\mathrm{b}}$ & $25.97^{\mathrm{ab}}$ & $25.66^{\mathrm{a}}$ \\
\hline 4 & CIP-395096.2 & $23.83^{\mathrm{bc}}$ & $11.50^{\mathrm{bc}}$ & $11.94^{\mathrm{e}}$ & $25.77^{\mathrm{c}}$ & $35.16^{\mathrm{a}}$ & $16.23^{\mathrm{c}}$ & $8.83^{\mathrm{c}}$ & $11.68^{\mathrm{e}}$ & $23.32^{\mathrm{C}}$ & $27.68^{\mathrm{a}}$ & $19.59^{d}$ \\
\hline 5 & CIP-395111.13 & $29.30^{\mathrm{a}}$ & $13.36^{\mathrm{b}}$ & $24.59^{\mathrm{a}}$ & $23.18^{d}$ & $27.41^{\text {bcd }}$ & $23.56^{\mathrm{b}}$ & $16.26^{\mathrm{ab}}$ & $23.51^{\mathrm{ab}}$ & $24.48^{\mathrm{c}}$ & $23.71^{\mathrm{b}}$ & $22.94^{\mathrm{b}}$ \\
\hline 6 & CIP-395011.2 & $29.36^{\mathrm{a}}$ & $13.70^{\mathrm{b}}$ & $14.32^{\mathrm{e}}$ & $7.63^{\mathrm{e}}$ & $28.98^{\mathrm{bc}}$ & $31.25^{\mathrm{a}}$ & $13.42^{\mathrm{b}}$ & $15.02^{\mathrm{d}}$ & $9.40^{\mathrm{d}}$ & $24.71^{\mathrm{ab}}$ & $18.78^{\mathrm{d}}$ \\
\hline 7 & CIP-396031.108 & $21.93^{\mathrm{dc}}$ & $11.29^{\mathrm{bc}}$ & $18.50^{\mathrm{d}}$ & $25.40^{\mathrm{c}}$ & $22.48^{\mathrm{d}}$ & $31.85^{\mathrm{a}}$ & $17.81^{\mathrm{a}}$ & $16.22^{\mathrm{d}}$ & $23.57^{c}$ & $24.02^{\mathrm{b}}$ & $21.31^{\mathrm{c}}$ \\
\hline \multirow[t]{6}{*}{8} & CIP-396004.225 & $23.52^{\mathrm{bc}}$ & $9.201^{c}$ & $21.43^{\mathrm{bc}}$ & $30.71^{b}$ & $24.16^{\text {cd }}$ & $25.47^{\mathrm{b}}$ & $18.13^{\mathrm{a}}$ & $9.19^{e}$ & $29.94^{\mathrm{b}}$ & $20.07^{c}$ & $21.18^{\mathrm{C}}$ \\
\hline & R square & 0.87 & 0.95 & 0.96 & 0.99 & 0.86 & 0.95 & 0.87 & 0.97 & 0.99 & 0.78 & 0.97 \\
\hline & P Level & 0.0001 & 0.0001 & 0.0001 & 0.0001 & 0.001 & 0.0001 & $<0.0001$ & $<0.0001$ & $<0.0001$ & 0.0025 & $<0.0001$ \\
\hline & LSD Value & 4.6881 & 2.7315 & 2.748 & 2.1175 & 5.0821 & 3.8119 & 3.3404 & 2.669 & 2.2571 & 3.0713 & 0.9798 \\
\hline & $\mathrm{CV}$ & 7.80 & 8.61 & 5.72 & 3.40 & 7.74 & 6.00 & 9.33 & 6.20 & 3.74 & 7.40 & 6.70 \\
\hline & Mean & 24.74 & 13.05 & 19.76 & 25.60 & 27.02 & 26.12 & 14.73 & 17.71 & 24.79 & 23.70 & 21.72 \\
\hline
\end{tabular}

*Means with the same letters within a column are not significantly different at p < 0.01 based on Fishers LSD. Where Ad1 \& Ad2; Ij1 \& Ij2, Sr1 \& Sr2; Db1 \& Db2 and Dt1 \& Dt2 were 2010 and 2011 rain fed season in Adet, Injibara, Serinka, Debrebirhan and Debretabor respectively. 
to $27.02 \mathrm{t} / \mathrm{ha}$ for Dt1 (Debretabor 2010) (Table 3) indicating that the influence of soil, temperature, precipitation, etc. on MTY.

The larger yield variation due to L, which is irrelevant to cultivar evaluation and mega environment investigation [10], justifies selection of site regression as the appropriate model for analyzing the multi-environment trials' data. The larger GL, relative to G confirmed the possible existence of different mega environments (Table 2). Hence, the MTY ( $\mathrm{t} / \mathrm{ha}$ ) data of potato was subjected to GGE biplot analysis.

\subsection{Stability Analysis}

The partitioning of GGE through GGE biplot analysis showed that PC1 and PC2 accounted for $51.24 \%$ and $20.02 \%$ of GGE sum of squares, respectively explaining a total of $71.24 \%$ variation (Figure 1). This revealed that there was a differential yield performance among potato genotypes across testing environments due to the presence of GEI. The Biplot analysis grouped the test locations into four groups. Genotypes that had PC1 scores > 0 were identified as higher yielding and those that had PC1 scores $<0$ were identified as lower yielding [11]. Thus, of the tested genotypes G2, G3, G8 and G1 were identified as high yielding (PC1 score > 0) while G4 and G6 as low yielding genotypes (PC1 score $<0$ ) (Figure 1). Unlike the PC1, PC2 was related to genotypic stability. Lower the absolute PC2, value more is the stability. Thus, G2 was the most stable genotype. Similarly, G3 and G8 also had better stability than others.



\footnotetext{
Figure 1. GGE-biplot based on genotype focused scaling for the trait MTY (t/ha), 2010-2011. N.b-Abbreviations in the biplot are as follows: (a) For environments: where Ad1 \& Ad2; Ij1 \& Ij2, Sr1 \& Sr2; Db1 \& Db2 and Dt1 \& Dt2 were 2010 and 2011 rain fed season in Adet, Injibara, Serinka, Debrebirhan and Debretabor respectively; (b) For genotypes: G1-Cip-396033.102, G2-CIP-395120.36, G3-CIP-396004.337, G4-CIP-395096.2, G5-CIP-395111.13, G6-CIP-395011.2, G7-CIP-396031.108 \& G8-CIP-396004.225.
} 
Relation among test environments: GGE-biplot which depends on environment focused scaling was portrayed to estimate the pattern of environments (Figure 2). According to [11] and [12], to visualize the relationship between environments, lines were drawn to connect the test environments to the biplot origin known as environment vector. The cosine of the angle between the two environments is used to approximate the relation between them. Thus, in Figure 2, positive correlations were found between test seasons (years) in a location as the angle between them was less than $90^{\circ}$. This indicated that year effect is minimal in the variation of MTY of potato. Similarly, positive correlation was observed between Sr1, Sr2, Ij1 and Ij2 testing environments. Reference [11] [12] reported, the presence of close associations between testing environments reveals that similar information about the genotype could be obtained from fewer test environments and hence there could be better potential to reduce testing cost under limited resources. Thus, indirect response to selection could be possible between Sr1, Sr2, Ij1 and Ij2 testing environments. In addition to the above the figure indicated that environment Debrebirhan (Db1 and Db2) was different from environment Adet (Ad1 and Ad2) and Debretabor (Dt1 and Dt2). Similarly, Environment, Debretabor (Dt1 and Dt2) and Serinka (Sr1 and Sr2) were also two different locations.

Discriminating ability and representativeness of test environments: The GGE biplot indicating discriminating ability and representativeness of test environments is indicated in Figure 2. The biplot (ranking testers based on discriminating ability and representativeness) helps to visualize the length of the environment vectors which is proportional to standard deviation within the respective environments on the biplot and also shows the discriminating ability of the environments [11]. Thus, among the testing environments Db1 and Db2 (Debrebirhan) with the longest vector were the most discriminating, while Dt2 and Ad1 were the least discriminating environments. Similarly, Sr1 and Sr2 had the second longest vector mean hence they were the second best discriminating environments.

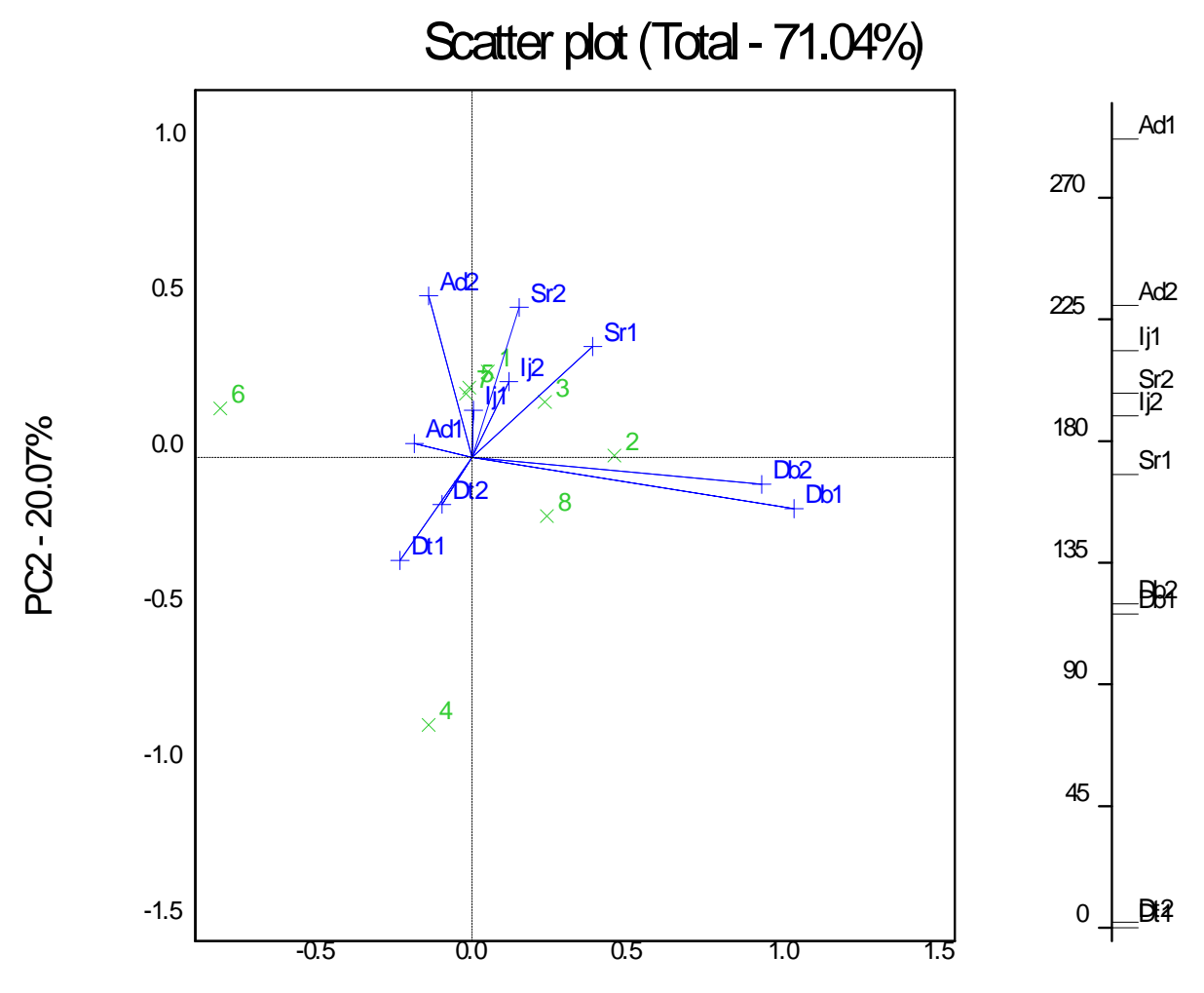

PC1- 50.98\%

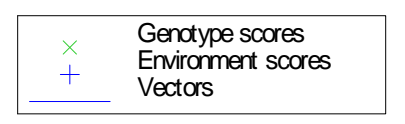

Figure 2. GGE-biplot view to show relationship among 10 testing environments, 2010-2011. 
Comparison biplot of test environments: This study is presented in Figure 3. The average environments coordinate (AEC) is a line that pas through the average environment (represented by small circle) and biplot origin. A test environment that has a small angle with the AEC is more representative of other test environments [11]. Thus, Sr1 and Sr2 (Serinka) were more representative than other testing locations. Since Sr1 and Sr2 had better discriminating power (Figure 2) as well as representativeness, it was identified as good testing environment for selecting widely adaptable and high yielding potato genotypes.

Mean performance and stability of potato genotypes: Figure 4 shows the AEC view of the GGE biplot. The average tester coordinate (ATC) separates genotypes with above average mean from below average means. Thus, genotypes with above average means were G2, G3, G5 and G7 on the figure, while G6 and G4 were genotypes which had below average mean performance. The shorter the genotype vector is more stable it is than others. Thus, among tested genotypes G3 was identified as high yielder and stable genotype while G6 and G4 were identified as low yielding with poor stability (long vector length).

Comparison of genotypes with ideal genotypes: An ideal genotype should have both high mean yield performance and high stability across environments. It is a genotype to be on average environmental coordinate (AEC) on positive direction and has vector length equal to the longest vector of the genotype and indicated by a arrow pointed to it [11] [12]. Thus, Figure 5 shows that G3 is nearest to the ideal genotype (the center of concentric circles) so it is more desirable than other tested genotypes.

\section{Comparison bipda (Total - 7104\%)}

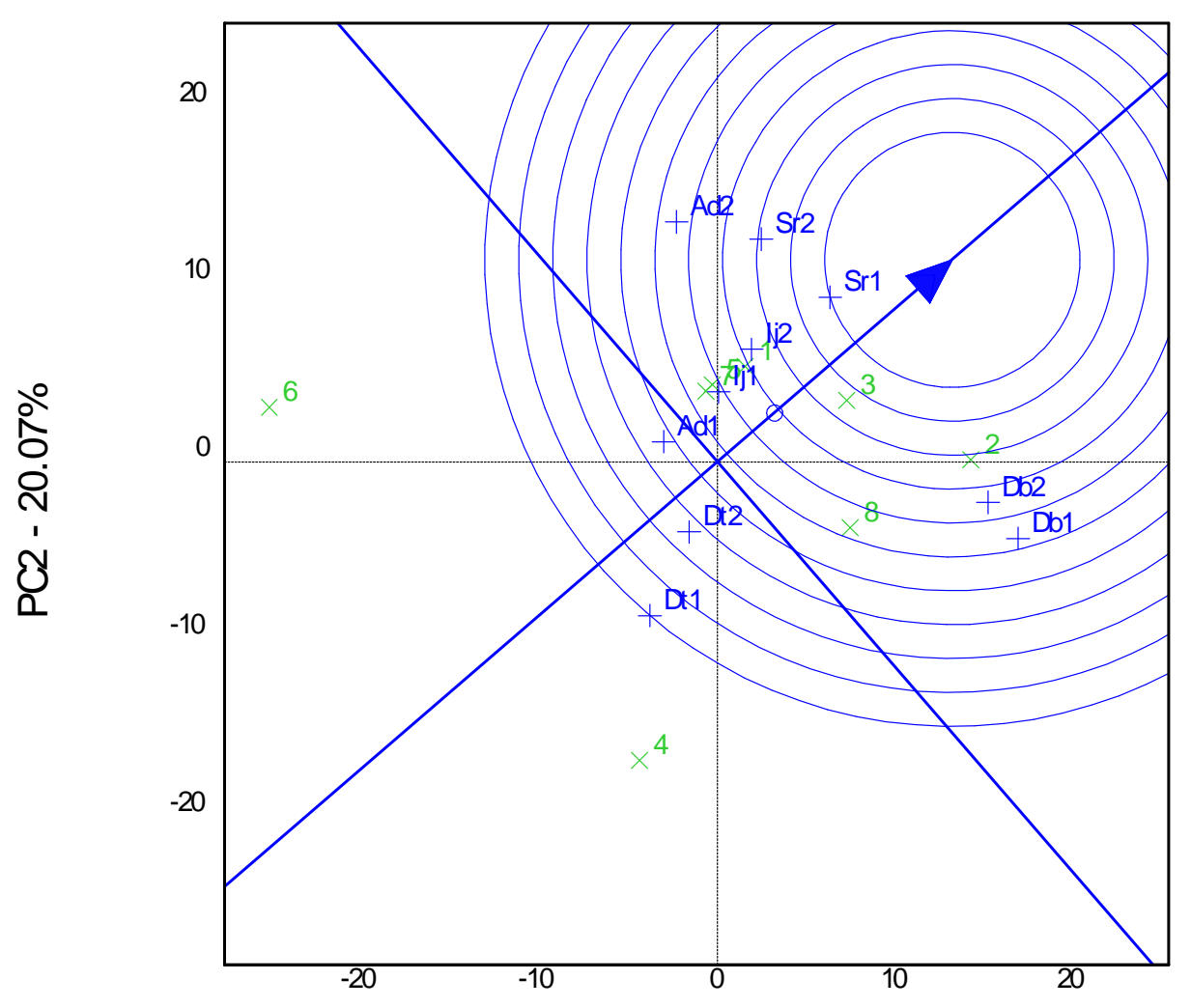

PC1- 50.98\%

\begin{tabular}{|cl|}
\hline$\times$ & Genotype scores \\
+ & Environment scores \\
0 & AEC \\
\hline
\end{tabular}

Figure 3. GGE-biplot showing a comparison of 10 testing environments with in ideal environment for the trait MTY (t/ha). 


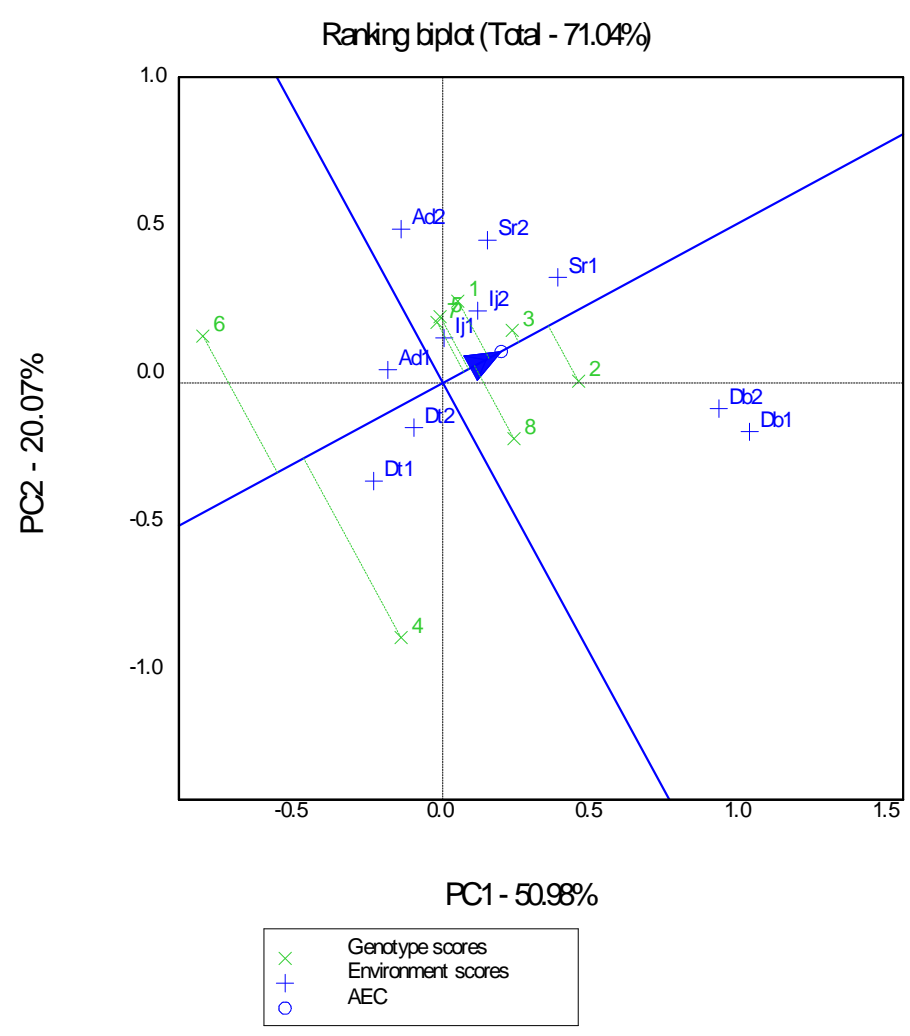

Figure 4. GGE ranking biplot shows the mean marketable tuber yield and stability performance of eight tested genotypes.

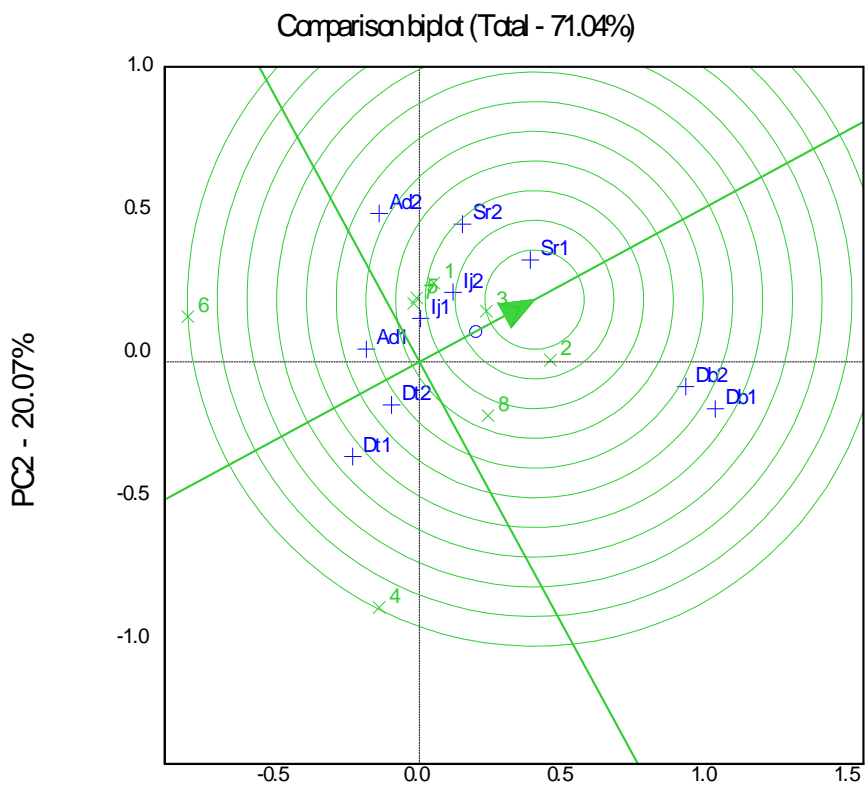

PC1- 50.98\%

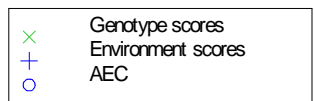

Figure 5. Comparison biplot views of marketable tuber yield of genotypes with the ideal genotype. 
Comparison between genotypes: On the GGE biplot, the performance of two genotypes can be visually compared by connecting their markers with a straight line and drawing perpendicular line/or equality line that passes through the biplot origin. Genotypes had better yield in environments that are located on its side of the equality line [11] [12]. In Figure 6, G3 and G6 were compared, the performance of G6 was better in Ad1, Ad2, Dt1 and Dt2 testing environments than G3 and vice versa in other testing environments. Since Table 3 indicated that Ad1, Ad2, Dt1 and Dt2 had mean MTY above average, G6 was relatively better adapted to high potential areas than G3.

Suitability of genotypes for particular environment using the "Which-Won-Where" function of a GGE biplot: Figure 7 shows the "which-won-where" view of this study. The vertex genotypes in this figure were G1, G2, G3, G4 and G6. Five rays divide the biplot in to five sectors. The vertex genotype for sector which encompasses Db1, Db2 and Sr1 was G2, for sector content Dt1 and Dt2 it was G4, for Ad1 and Ad2 it was G6, for Ij1, Ij2, and Sr2 was G3/G1 implying that these genotypes were the winning genotypes for respective environments. However, "which-won-where" views of the GGE biplot of each year were not repeated across years (Figure 8). In this case GE cannot be exploited, rather it must be avoided by selecting high yielding and stable genotypes across target environments [13]. Thus, G3 had high mean marketable tuber yield and stability across test locations and years, hence G3 was identified as high yielder and widely adaptable genotype.

\section{Conclusions}

Among testing environments, the minimum mean marketable tuber yield (t/ha) was obtained at Injibara (2010 season) while the maximum yield was at Debretabor (2010 season). The mean performance of tested genotypes

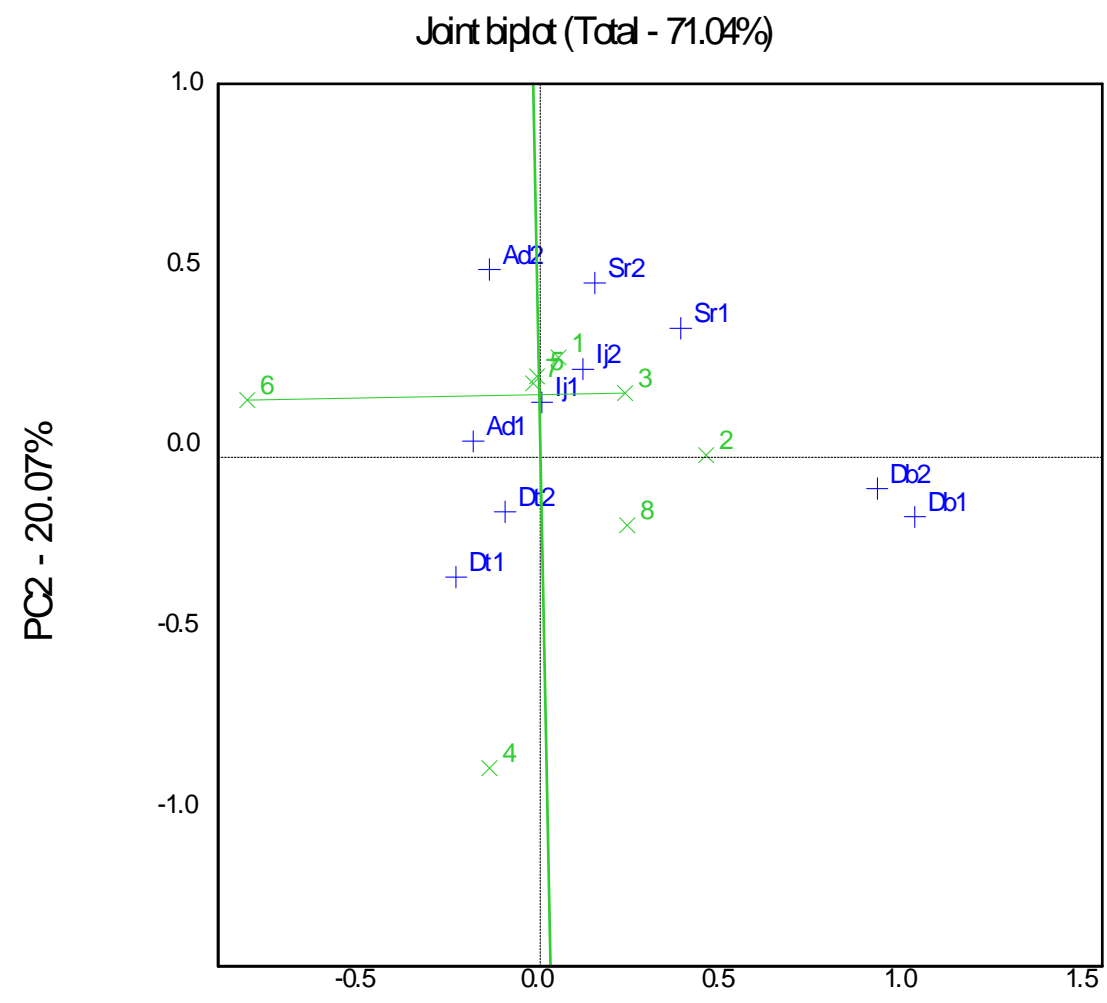

PC1- 50.98\%

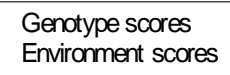

Figure 6. Comparison biplot of G3 with G6 for their marketable tuber yield (t/ha) in different environments. 


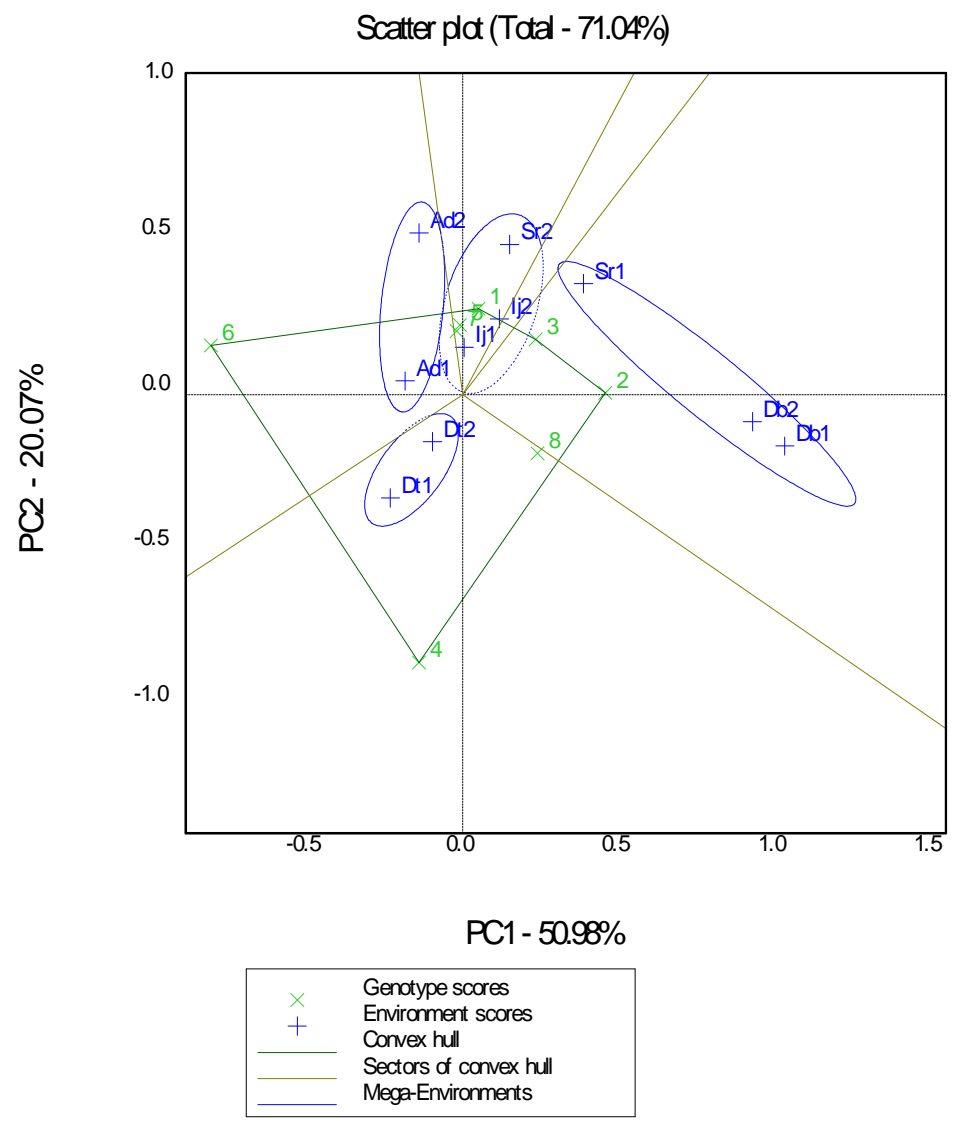

Figure 7. The which-won-where view of the GGE biplot of marketable tuber yield (t/ha), 2010-2011.

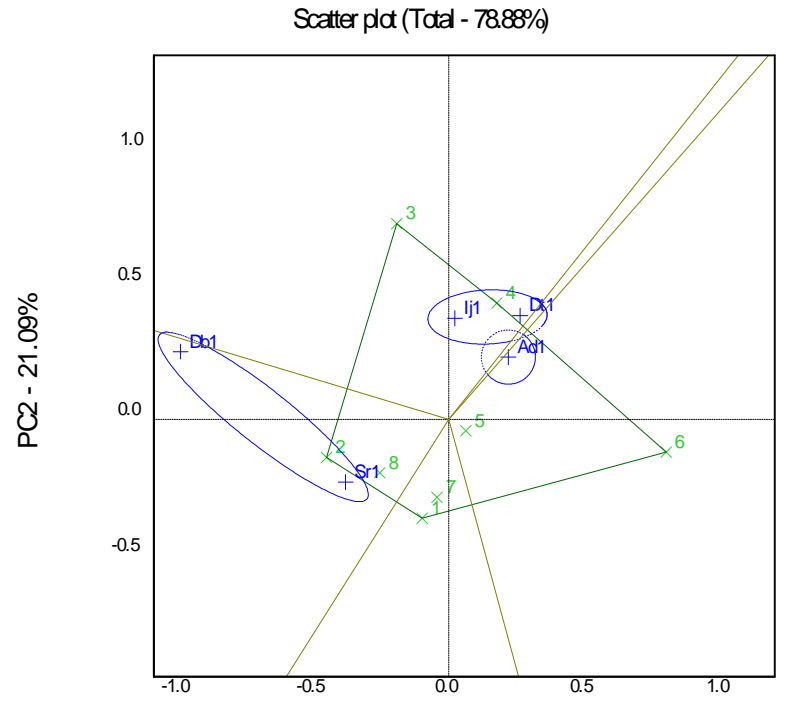

PC1- $57.78 \%$

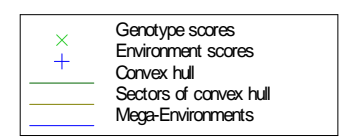

Scatter plot (Tota - 74.41\%)

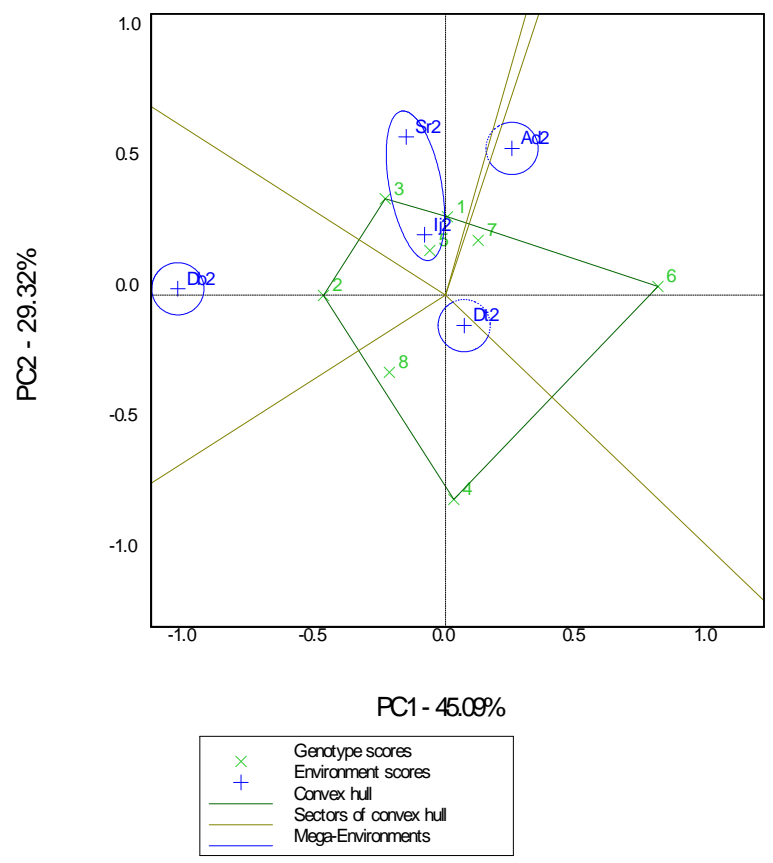

Figure 8. Which won where view of GGE biplot of eight genotypes over five locations during 2010 (left) and 2011(right). 
across all environments ranged from $18.78 \mathrm{t} / \mathrm{ha}$ for G6 (CIP-395011.2) to $25.66 \mathrm{t} / \mathrm{ha}$ for G3 (CIP-396004.337) with an average mean yield of $21.72 \mathrm{t} / \mathrm{ha}$.

The analysis of variance across locations and years indicated that location was the most important source of yield variation. It accounted for $46.90 \%$ of the total variance (G, L, Y and GEI). The contribution of GEI to the yield variation was $44.07 \%$ while that of $\mathrm{G}$ was $8.83 \%$. The GEI component was partitioned by GGE biplot. The first two principal components (PC1 and PC2) obtained by singular value decomposition of the centered data explained $71.26 \%$ of the total variability caused by (G + GE). Of which, PC1 and PC2 accounted for 51.24\% and $20.02 \%$ variability, respectively.

Biplot view of relation among test environments of this study showed that Serinka (Sr1 and Sr2) was more associated with environment Injibara (Ij1 and Ij2). Thus, indirect response to selection could be possible in these environments. Among the testing environments, Serinka ( $\mathrm{Sr} 1$ and $\mathrm{Sr} 2$ ) is an ideal testing location to identify stable and high yielding genotypes for the region.

Mean performance and stability biplot of tested genotypes across test environments indicated that G3 had the highest mean yield as well as stability while G6 and G4 had the lowest mean yield and less stability.

In this study, crossover GEI was not repeatable across years. Thus mega environment classification was not possible. Therefore, based on high yield potential and stability across test environments, G3 (CIP-396004.337) was selected as the best genotype for testing sites.

\section{Acknowledgements}

The authors would like to acknowledge the financial support provided by Adet Agricultural Research Center, Spanish Agency for International Development Cooperation (AECID) and SWISHA. The authors also highly appreciate and acknowledge the efforts of potato team of respective agricultural research centers for managing the field trials and collecting data. We use this opportunity to thank Dr. Tesfaye Abebe for his guidance and provision of chemicals and materials during laboratory work. Our appreciation also goes to Yemisrach Melkie for her help in providing computer service.

\section{References}

[1] Berga, L., Gebremedhin, W., Teriessa, J. and Bereke, T. (1992) Potato Agronomy Research. In: Herath and Lemma, Eds., Horticulture Research and Development in Ethiopia, Proceedings of the $2^{\text {nd }}$ National Horticultural Workshop of Ethiopia, Institute of Agricultural Research, Addis Ababa, 2-5 February 1992, 182-196.

[2] CSA (2010) The Federal Democratic Republic of Ethiopia Central Statistical Agency Agricultural Sample Survey. Volume I: Report on Area and Production of Major Crops. Meher Season’s Statistical Bulletin, Addis Ababa, 221.

[3] Yilma, S. (1989) The Potential of True Potato Seed in Potato Production in Ethiopia. Acta Horticulturae, 270, $389-394$.

[4] FAO (2012) Food and Agriculture Organization of the United Nations. http://faostat.fao.org/

[5] Tesfaye, A. and Yigzaw, D. (2008) Review of Crop Improvement Research Achievements and Future Focus in Parts of Western Amhara Region: The Case of Adet. Tesfaye, A., Ed., Proceedings of the $1^{\text {st }}$ Amhara Region Regional Workshop on Potato Research and Development Achievements and Transfer Experiences and Future Directions, Bahir Dar, 22-24 December 2008, 85-101.

[6] Ding, M., Tier, B. and Yan, W. (2007) Application of GGE Biplot Analysis to Evaluate Genotype, Environment and GxE Interaction on P. radiata: A Case Study.

http://proceedings.com.au/afgc/slides\%20(PDF)/thurs\%201600\%20ding.pdf

[7] Tesfaye, A. (2010) Potato Production and Post Harvest Handling. Tis Abay Publishing Limited, Bahir Dar, 82.

[8] SAS (2002) System Analysis Software. V 9. SAS Institute INC., Cary.

[9] GenStat (2011) Genstat Procedure Library Release PL22.1. 14th Edition, VSN International Ltd., Hemel Hempstead.

[10] Yan, W., Hant, L.A., Qinglai, S. and Szalvincs, Z. (2000) Cultivar Evaluation and Megaenvironment Investigation Based on the GGE Biplot. Crop Science, 40, 597-605. http://dx.doi.org/10.2135/cropsci2000.403597x

[11] Yan, W. and Tinker, N.A. (2006) Biplot Analysis of Multi-Environment Trial Data: Principles and Applications. Canadian Journal of Plant Science, 86, 623-645. http://dx.doi.org/10.4141/P05-169

[12] Kaya, Y., Akcura, M. and Taner, S. (2006) GGE-Biplot Analysis of Multi-Environment Yield Trials in Breed Wheat. Turkish Journal of Agriculture and Forestry, 30, 325-337.

[13] Yan, W., Kang, M.S., Woods, S. and Cornelius, P.L. (2007) GGE Biplot vs AMMI Analysis of Genotype by Environment Data. Crop Science, 47, 643-655. http://dx.doi.org/10.2135/cropsci2006.06.0374 